\title{
A personal memory aid augmenting the 'My five moments for hand hygiene' concept
}

\author{
HS Sax
}

From International Conference on Prevention \& Infection Control (ICPIC 2011)

Geneva, Switzerland. 29 June - 2 July 2011

\section{Introduction / objectives}

Human memory capacity is limited and even relatively simple concepts are not easily retained if not central to the individual's emotional engagement. The 'My five moments for hand hygiene' (Sax H, et al. J Hosp Infect 2007;67:9-21) has been designed to be simple and 'sticky'. But even so, as informal surveys show, only 2 of 5 hand hygiene indications are accessible in active memory and correctly reproduced by healthcare workers upon request.

\section{Methods}

Search for a simple memory aid using concepts of emotional design and human factors engineering principles through a heuristic try and error design process.

\section{Results}

The solution is simple, almost for-free, and in most basic healthcare settings universally available. It enhances memorizing five distinct indications for hand hygiene and correct use of disposable gloves through a phase of personal physical challenge, joy of final success, simplicity and the principal of chunking the 6 items (5 indications for hand hygiene and correct glove use) into 3 items. Preliminary small-scale testing shows a strong memory-enhancing effect.

\section{Conclusion}

This invention has a lifesaving potential at near zero cost. Very simple design solutions according to human factors principles can be very effective.

\section{Disclosure of interest}

None declared.

Infection control program, University of Geneva Hosptials and Medical Faculty, Geneva, Switzerland
Published: 29 June 2011

doi:10.1186/1753-6561-5-S6-P28

Cite this article as: Sax: A personal memory aid augmenting the 'My five moments for hand hygiene' concept. BMC Proceedings 2011 5(Suppl 6):P28.
Submit your next manuscript to BioMed Central and take full advantage of:

- Convenient online submission

- Thorough peer review

- No space constraints or color figure charges

- Immediate publication on acceptance

- Inclusion in PubMed, CAS, Scopus and Google Scholar

- Research which is freely available for redistribution
() Biomed Central

\section{Biomed Central}

